\title{
Minimum light requirements for growth in Ulva lactuca
}

\author{
Kaj Sand-Jensen* \\ Freshwater Biological Laboratory, University of Copenhagen, Helsingersgade 51, DK-3400 Hillerød, Denmark
}

\begin{abstract}
Growth and photoadaptation were measured in Ulva lactuca discs kept in the laboratory at continuous photon flux densities between 0 and $55 \mu \mathrm{mol} \mathrm{m} \mathrm{m}^{-2} \mathrm{~s}^{-1}$ at $7^{\circ} \mathrm{C}$. The light compensation point for growth $\left(I_{C}\right)$ was ca $2.5 \mu \mathrm{mol} \mathrm{m}{ }^{-2} \mathrm{~s}^{-1}$ and was similar to the minimum light compensation point for photosynthesis of $U$. lactuca. $I_{c}$ corresponded to only $0.5 \%$ of surface light in Danish waters during summer and 2 to $4 \%$ at $7^{\circ} \mathrm{C}$ in autumn. Photoadaptation was regulated mainly by changes in light absorptance and dark respiration rates whereas quantum efficiency was approximately constant. Absorptance was highest at intermediate light levels $\left(2.5\right.$ to $\left.8.8 \mu \mathrm{mol} \mathrm{m} \mathrm{m}^{-2} \mathrm{~s}^{-1}\right)$ and coincided with maximum efficiencies for growth ( $\mathrm{ca} 0.024 \mathrm{~mol} \mathrm{C}$ fixed per mol incident photon and $0.056 \mathrm{~mol} \mathrm{C}$ fixed per mol photon absorbed). Dark respiration rates were linearly related to growth rate and doubled from low to high light acclimated plants. Respiratory maintenance costs, estimated from the carbon growth balance of non-growing $U$. lactuca in very weak light $\left(<0.3 \mu \mathrm{mol} \mathrm{m} \mathrm{m}^{-2} \mathrm{~s}^{-1}\right)$, were low at 0.0094 to 0.012 mol C respired (mol cell C) $)^{-1} \mathrm{~d}^{-1}$ (half-life of cellular carbon $=58$ to $74 \mathrm{~d}$ ) and corresponded to the experimentally derived values. These low maintenance costs are essential to maintain a low $I_{c}$ value and would also allow $U$. lactuca to survive extended periods in the dark. The results do not conform with the previous view of Ulva lactuca as a classic ruderal sun species, but show a high capacity for growth in the shade.
\end{abstract}

\section{INTRODUCTION}

In aquatic ecology and physiology, light is a key factor which often sets the depth limit of plant distribution and exerts the major control on their photosynthesis and growth (Sand-Jensen 1988a). The limit of the euphotic zone for phytoplankton, i.e. the maximum depth where net growth is possible, was previously regarded as being at $1 \%$ of surface light (Steemann Nielsen 1975). During summer in temperate regions, the daily average of photon flux density (PAR) at the $1 \%$ depth is equivalent to 4 to $5 \mu \mathrm{mol} \mathrm{m} \mathrm{m}^{-2} \mathrm{~s}^{-1}$ of continuous light (Geider et al. 1986). However, several investigations show that natural phytoplankton populations grow and may develop an extensive biomass at the $1 \%$ (Fee 1976, Pick et al. 1984) and even lower light level (Venrick et al. 1973), provided that the light climate is stable over days and weeks so that long-term shade adaptation can occur as in non-mixed depth strata of a stabilized water column (Richardson et al.

\footnotetext{
- Present address: Botanical Institute, University of Aarhus, Nordlandsvej 68, DK-8240 Risskov, Denmark
}

1983). Recent laboratory work has shown growth of microalgae at even lower photon flux densities of 0.1 to $1 \mu \mathrm{mol} \mathrm{m}{ }^{-2} \mathrm{~s}^{-1}$ (Geider et al. 1985, 1986, and references therein) stressing that the $1 \%$ light level should be used as a point of reference and not as a lower limit to growth (Richardson et al. 1983).

There is very limited experimental work on minimum light requirements of macrophytes. Crude estimates of minimum light requirements of submerged species are, therefore, deduced from the amount of light available at the maximum depth of penetration. The weaknesses of this approach are that the maximum depth is not always set by light availability and that large variations are caused by seasonal variability in the light climate and thus also by the seasonal growth pattern of the species. Marine macroalgae have depth limits for growth that resemble those for phytoplankton. Massive brown algae (e.g. Laminarians) grow down to between 0.7 and $1.4 \%$ of surface light, and some crustose red and green algae grow even further down where only 0.05 to $0.1 \%$ of surface light remains (Lüning \& Dring 1979). The minimum light requirements of freshwater macrophytes are usually much higher (Sand-Jensen 
1988a). Based on an extensive survey, Chambers \& Kalff (1985) found that the depth penetration of submerged freshwater macrophytes in temperate lakes on average corresponded to $21 \%$ of surface light for rooted angiosperms, $18 \%$ for bryophytes, and $11 \%$ for charophytes. Differences in depth penetration among the groups are probably due mainly to different light requirements, even though higher temperature requirements in angiosperms may also be important, and prevent them from extending into hypolimnetic layers (Moeller 1980, Barko et al. 1982).

Light requirements of shade-adapted plants are regulated by 3 important features: (1) light harvesting ability, (2) quantum efficiency, and (3) respiration. There is no information about quantum efficiency in relation to incident light level for growth of submerged macrophytes. The literature for terrestrial higher plants and aquatic microalgae does not indicate that quantum efficiency is higher for shade than for sun species or for shade-adapted than for sun-adapted plants of the same species (Björkman 1981, Raven 1984a). To optimize light utilization for growth of macrophytes in low light it is therefore essential for maximum light absorption by photosynthetic pigments (cf. 1) to be achieved by minimum tissue investments and operational costs (cf. 3). The higher light requirements for rooted angiosperms relative to bryophytes and charophytes are not surprising due to their possession of non-photosynthetic structures (roots, rhizomes, transport and supportive tissue). Likewise, the reduced self-shading both within and among the photosynthetic tissue of macroalgae with a thin thallus (e.g. charophytes and Ulva) is also likely to lead to a better performance in low light than for macroalgae with a thick and structurally complex thallus (e.g. Laminaria and Codium) or for angiosperms with overlapping mutually shading leaves (e.g. Elodea), even though the absorptance of incident light may be higher for the latter (Ramus 1978).

The present experimental investigation was conducted with unattached Ulva lactuca, which has several advantages. It is easy to cultivate, areal growth rates are easily measured, and it is possible to attain homogeneous experimental material. My specific objectives were: (1) To determine the minimum light requirements for growth $\left(\mathrm{I}_{\mathrm{c}}\right)$, taking into account possible changes in carbon content per unit area, which were not fully considered in a previous work (Vermaat \& Sand-Jensen 1987). (2) To determine the importance of different photoadaptive responses (light absorptance, maintenance costs, quantum efficiency) in regulating the $I_{c}$ value. (3) To compare $I_{c}$ values, light utilization efficiencies and maintenance costs derived from growth experiments with those measured in photosynthetic experiments with the same material acclimated to different light levels (Sand-Jensen 1988b).

\section{MATERIAL AND METHODS}

Free-floating UIva lactuca was collected in late autumn in the outer parts of Roskilde Fjord, a eutrophic Danish estuary (Borum 1985). The alga was grown in freshly collected filtered seawater from the collection site (16 to $18 \%$ salinity) enriched with $\mathrm{N}$ and $\mathrm{P}$ to prevent nutrient limitation (1 $\mathrm{mg} \mathrm{NH}_{4} \mathrm{NO}_{3}-\mathrm{Nl}^{-1}, 0.1 \mathrm{mg}$ $\left.\mathrm{PO}_{4}-\mathrm{P}^{-1}\right)$. Circular $U$. lactuca discs $(17 \mathrm{~mm}$ in diameter) were punched from the collected larger specimens with a sharpened perspex tube and grown in flat culture bottles $(18 \times 10 \times 1 \mathrm{~cm})$ in the dark and under continuous illumination from cool-white fluorescent tubes at incident photon flux densities of $0.28,0.83,2.5$, $8.8,25$ and $55 \mu \mathrm{mol} \mathrm{m} \mathrm{m}^{-2} \mathrm{~s}^{-1}$ (PAR, 400 to $700 \mathrm{~nm}$ ), as measured with a $2 \pi$ quantum sensor (LI-COR 185A). Water from a $10 \mathrm{l}$ reservoir was continuously circulated through the culture bottles at a rate of ca $40 \mathrm{ml} \mathrm{min}^{-1}$. The reservoir was aerated and the water renewed twice a week. The culture bottles had their large flat surface exposed towards the light source and were completely covered with neutral density plastic filters to create the range of incident light levels. Light transmission through the shaded culture bottles was determined at high light levels to ensure sufficient sensitivity. The actual light level was then calculated as the product of transmission and full illumination in the culture facility (i.e. $55 \mu \mathrm{mol} \mathrm{m} \mathrm{m}^{-2} \mathrm{~s}^{-1}$ ).

The experiments were carried out in 2 replicate series, each consisting of a reservoir and culture bottles at the 7 light levels. Each culture bottle initially contained 4 Ulva lactuca discs. In treatments with fast growth, new discs were punched from old discs exceeding $25 \mathrm{~mm}$ in diameter to minimize self-shading among discs and prevent uneven conditions among treatments. $U$. lactuca discs grow at the same rate over the entire surface area. Nevertheless, new discs were punched at random, including both the central and marginal parts of old discs, to make sure that new or old tissues were not preferentially transferred by this procedure. The cultures were placed in a cooling system and kept at $7^{\circ} \mathrm{C}$.

Surface area and light absorptance were measured weekly on all discs as described by Vermaat \& SandJensen (1987). Absorptance is defined as the fraction of incident photons absorbed by the thallus. Discs grew sufficiently fast at $8.8,24.8$ and $55.0 \mu \mathrm{mol} \mathrm{m} \mathrm{m}^{-2} \mathrm{~s}^{-1}$ to make certain that the expansion of surface area was exponential with time. Areal growth rates were, therefore, determined from linear regression of $\ln$ (surface area) on time. Dry weight and carbon content were measured at the start and after 14,35 and 70 to $80 \mathrm{~d}$ of growth. Carbon content was measured by dry combustion of dried subsamples in a continuous flow of $\mathrm{O}_{2}$-gas passing through the combustion furnace $\left(700^{\circ} \mathrm{C}\right)$ and 
carrying the released $\mathrm{CO}_{2}$ into an infrared gas analyzer (ADC $225 \mathrm{mk}$ 3) connected to a Shimadzu C-R3A integrator. Since Ulva lactuca discs may grow slightly in surface area without gaining weight, I calculated the growth rate in carbon units by combining the rates of changes in surface area and carbon content per unit of surface area. Dark respiration rates were measured in duplicate after $35 \mathrm{~d}$ of photoadaption, by incubations of single discs in closed stirred bottles $(30 \mathrm{ml})$, following changes in dissolved inorganic carbon over $18 \mathrm{~h}$ (Vermaat \& Sand-Jensen 1987)

\section{RESULTS}

The growth rate in surface area of Ulva lactuca increased with incident light level and small, mainly positive values, were found in very weak light (Fig. 1). The surface area increased with time at incident photon flux densities of $2.5 \mu \mathrm{mol} \mathrm{m} \mathrm{m}^{-2} \mathrm{~s}^{-1}$ or more. Below this level, discs also tended to increase in area but at the expense of internal carbon reserves. The specific growth rate in carbon units (Fig. 2) was therefore negative in the dark (ca $\left.-0.012 \mathrm{~d}^{-1}\right)$, zero at ca $2.5 \mu \mathrm{mol}$ $\mathrm{m}^{-2} \mathrm{~s}^{-1}$, and maximum at $55 \mu \mathrm{mol} \mathrm{m} \mathrm{m}^{-2} \mathrm{~s}^{-1}$ at ca 0.057 $\mathrm{d}^{-1}$ (doubling time ca $11 \mathrm{~d}$ ). The downward curvature of the growth-light curve (Fig. 2) showed that photoadaptation occurred and resulted in higher growth rate per unit incident light at 8.8 than at $55 \mu \mathrm{mol} \mathrm{m} \mathrm{m}^{-2} \mathrm{~s}^{-1}$.

Photoadaptation was mainly due to changes in light

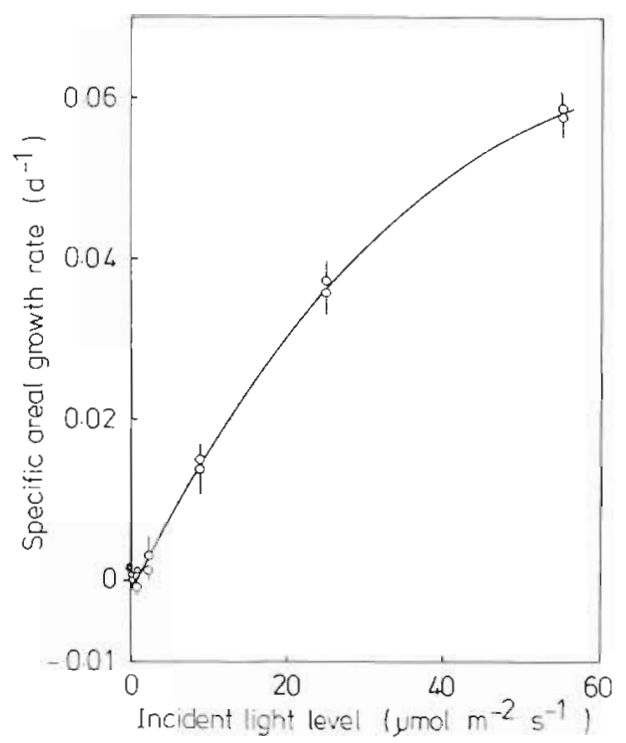

Fig. 1. Ulva lactuca. Specific areal growth rate as a function of incident light level at $7^{\circ} \mathrm{C}$. U. lactuca grew exponentially in surface area and areal growth rate was calculated by linear regression of the rate of increase in surface area with time (ln $\left.A_{t}-\ln A_{0} t\right)$. Mean values $\pm 95 \% C L$ of at least 24 individual measurements between 14 and $70 \mathrm{~d}$ of acclimation

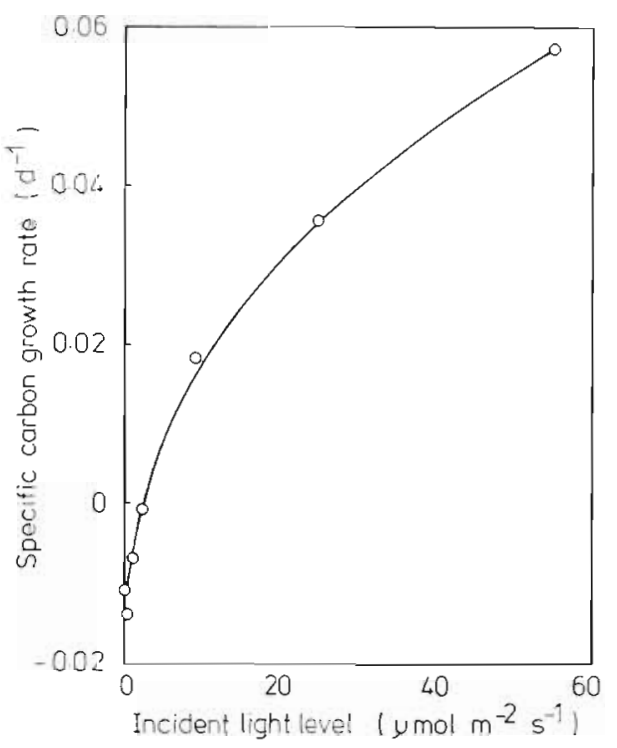

Fig. 2. Ulva lactuca. Specific carbon growth rate as a function of incident light level at $7^{\circ} \mathrm{C}$. Carbon growth rate was calculated as the rate of increase in carbon content $\left(\ln \mathrm{C}_{t}-\ln \mathrm{C}_{0}: \mathrm{t}\right)$ by following changes in surface area and carbon content per unit surface area between 14 and $70 \mathrm{~d}$ of acclimation

absorptance and dark respiration (Table 1). Fractional absorptance, as an average for visible light (400 to $700 \mathrm{~nm}$ ), was highest (0.51) in Ulva lactuca grown at an intermediate photon flux density of $8.8 \mu \mathrm{mol} \mathrm{m} \mathrm{m}^{-2} \mathrm{~s}^{-1}$. Dark respiration rate was 2 times faster in high than in low light but was better correlated with net carbon balance than with incident PFD level. Dark respiration rate increased linearly with net carbon balance (or

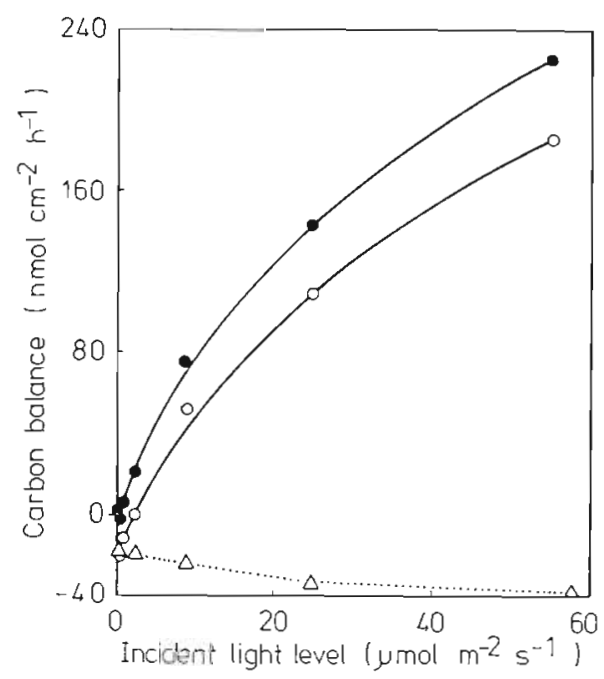

Fig. 3. Ulva lactuca. Carbon balance as a function of incident light level at $7^{\circ} \mathrm{C}$. Net carbon balance (C-) was calculated from the rate of change in surface area and carbon content per unit surface area. Dark respiration rate $(\Delta \cdots . . . \Delta)$ was determined experimentally. Gross carbon balance $(\bullet)$ was the sum of net carbon balance and dark respiration 
Table 1 Ulva lactuca. Light absorptance, carbon growth balance and efficiency in utilization of incident and absorbed photons during growth from 14 to $70 \mathrm{~d}$ after exposure to different incident light levels. Mean initial light absorptance was $0.34 \pm 0.04$ $( \pm \mathrm{SD}, n=8$ ). Mean dark respiration ( $\pm \mathrm{SD}, \mathrm{n}=2$ ) was measured at Day 35. Net carbon growth balance was calculated from changes with time in surface area and area-specific carbon content. Gross carbon balance was the sum of net carbon balance and dark respiration

\begin{tabular}{|ccccccc}
\hline $\begin{array}{l}\text { Incident light } \\
\left(\mu \mathrm{mol} \mathrm{m} \mathrm{m}^{-2} \mathrm{~s}^{-1}\right)\end{array}$ & $\begin{array}{c}\text { Light } \\
\text { absorptance }\end{array}$ & \multicolumn{2}{c}{$\begin{array}{c}\text { Carbon growth balance } \\
\left.\text { (nmol C cm } \mathrm{h} \mathrm{h}^{-1}\right)\end{array}$} & Gross growth efficiency (mol C [mol photon] ${ }^{-1}$ ) \\
\hline 55.00 & $0.308 \pm 0.046$ & $39.0 \pm 8.6$ & 186.1 & 225.1 & 0.011 & Absorbed photons \\
\hline 24.75 & $0.396 \pm 0.032$ & $33.8 \pm 1.9$ & 109.5 & 143.3 & 0.016 & 0.037 \\
8.80 & $0.514 \pm 0.018$ & $24.1 \pm 2.6$ & 51.6 & 75.1 & 0.024 & 0.041 \\
2.48 & $0.412 \pm 0.059$ & $20.4 \pm 2.7$ & 0 & 20.4 & 0.023 & 0.047 \\
0.83 & $0.344 \pm 0.052$ & $17.2 \pm 3.1$ & -12.1 & 5.1 & 0.017 & 0.049 \\
0.28 & $0.312 \pm 0.041$ & $19.7 \pm 1.0$ & -22.8 & -3.1 & & Incident photons \\
0 & $0.283 \pm 0.023$ & $18.8 \pm 0.1$ & -17.8 & 1.0 & & \\
\hline
\end{tabular}

growth rate) according to the regression formula (in nmol $\left.\mathrm{C} \mathrm{cm}^{-2} \mathrm{~h}^{-1}\right)$ :

Dark respiration $=0.104 \times$ Netcarbon balance $+20.3(1)$

$$
(r=0.98, p<0.001) \text {. }
$$

Maintenance costs were estimated as the carbon balance in non-growing Ulva lactuca discs. These estimates were in close agreement with direct measurements of dark respiratory rates of $U$. lactuca acclimated to 0 and $0.28 \mu \mathrm{mol} \mathrm{m} \mathrm{m}^{-2} \mathrm{~s}^{-1}$, where photosynthetic carbon gains were negligible (Table 1).

As these 2 methods compared favourably it was possible to estimate the gross carbon balance, defined as the sum of net carbon balance and dark respiration (with positive sign; Table 1 and Fig. 3). Gross carbon balance was zero in the dark and increased with incident light at a gradually falling rate. Gross efficiency of carbon fixation was estimated per unit of both incident and absorbed photons (Table 1). There was a considerable uncertainty associated with these estimates at low growth rates and no estimates were possible at 0.28 umol m $\mathrm{m}^{-2} \mathrm{~s}^{-1}$ and in darkness. Growth efficiency per unit of incident photons decreased more than 2-fold from intermediate to high incident light levels. This reduction was mainly due to the parallel effects of reduction in light absorptance and beginning of light saturation of the photosynthetic processes (Sand-Jensen 1988b).

\section{DISCUSSION}

\section{Light curve for growth and quantum efficiency}

The difference between growth rates of Ulva lactuca in low light as measured by surface area or by carbon illustrated how important it was to use carbon for growth measurements and to continue experiments over extended periods to minimize transient effects when light exposure was changed. Similar precautions are probably relevant for microalgae which may continue to multiply when transferred from high to very low light but with cell carbon gradually diminishing.

The light curve for carbon growth in Ulva lactuca had a negative curvature over the range of incident light levels. It differed from those of microalgae where light and growth were linearly related in low light followed by saturation in high light (Geider et al. 1985). Under the present experimental conditions (continuous light at $7^{\circ} \mathrm{C}$ ) there was an optimum range for photoadaptation between 2.5 and $8.8 \mu \mathrm{mol} \mathrm{m} \mathrm{m}^{-2} \mathrm{~s}^{-1}$ where light absorptance and utilization efficiency of incident photons were highest (Table 1). Below that range, at $0.83 \mu \mathrm{mol} \mathrm{m} \mathrm{m}^{-2} \mathrm{~s}^{-1}$ or less, light limitation resulted in loss of weight and eventually pigmentation. The weight loss was extremely slow, $-0.012 \mathrm{~mol} C$ lost (mol cell C) $)^{-1} \mathrm{~d}^{-1}$ in the dark and $-0.0065 \mathrm{~d}^{-1}$ at $0.83 \mu \mathrm{mol}$ $\mathrm{m}^{-2} \mathrm{~s}^{-1}$, corresponding to half-lives of the carbon content of 58 and $107 \mathrm{~d}$, respectively. The initial light absorptance was maintained at a photon flux density of $0.83 \mu \mathrm{mol} \mathrm{m} \mathrm{m}^{-2} \mathrm{~s}^{-1}$ (Table 1 ) but absorptance dropped from 0.34 to 0.28 over $56 \mathrm{~d}$ in the dark. Because respiratory maintenance costs $\left(\mathrm{r}_{\mathrm{m}}\right)$ are so low in $U$. lactuca at $7^{\circ} \mathrm{C}$ it will tolerate extended periods in low light or darkness and rapidly resume growth upon exposure to high light. The typical fluctuating light conditions in the field make a combination of dark tolerance and a low light compensation point for growth $\left(I_{c}\right)$ a suitable combination for survival and growth in the shade. This combination is likely to result from the direct proportionality between $I_{C}$ and $r_{m}$ (Eq. 2 below).

At the highest light level (55 umol $\left.\mathrm{m}^{-2} \mathrm{~s}^{-1}\right)$, growth was much faster. However, utilization efficiencies of incident photon were lower because light absorptance dropped (Table 1) and light was no longer fully limiting to growth (Sand-Jensen 1988b) 
The efficiency of light utilization can be further evaluated by comparison with photosynthetic experiments with the same light-acclimated material (SandJensen 1988b). Growth was fully light-limited at 8.8 umol $\mathrm{m}^{-2} \mathrm{~s}^{-1}$ or less and was comparable with photosynthetic experiments performed under similar low light levels. Growth and photosynthetic efficiencies in carbon units were in close agreement at these incident light levels. Thus, photosynthetic efficiencies ranged from 0.017 to $0.030 \mathrm{~mol} \mathrm{C}$ (mol incident photon) ${ }^{-1}$ and 0.045 to $0.059 \mathrm{~mol} \mathrm{C}$ (mol absorbed photon) $)^{-1}$ at the different light acclimation levels (Sand-Jensen 1988b).

\section{Light compensation point for growth}

The light compensation point for growth $\left(I_{c}\right)$ was ca $2.5 \mu \mathrm{mol} \mathrm{m} \mathrm{m}^{-2} \mathrm{~s}^{-1}$, equivalent to a daily dose of ca 0.22 mol photons $\mathrm{m}^{-2}$. This value corresponds to $0.5 \%$ of daily surface light in Danish waters during summer and 2 to $4 \%$ of daily surface light during October and November, when Ulva lactuca was collected (PAR measurements at a nearby metereological center). Growth of $U$. lactuca is, therefore, possible deep down into the euphotic zone, in agreement with observations of fresh looking $U$. lactuca in deep water at very low light (Sand-Jensen unpubl.).

The $I_{c}$ value of $2.5 \mu \mathrm{mol} \mathrm{m} \mathrm{m}^{-2} \mathrm{~s}^{-1}$ may represent a small overestimation due to shading among overlapping discs in the culture flasks. Nevertheless, this value corresponded closely to $I_{c}$ for photosynthesis at 2.3 to $2.6 \mu \mathrm{mol} \mathrm{m} \mathrm{m}^{-2} \mathrm{~s}^{-1}$ in carbon exchange experiments and 1.5 to $2.2 \mu \mathrm{mol} \mathrm{m} \mathrm{m}^{-2} \mathrm{~s}^{-1}$ in oxygen exchange experiments with Ulva lactuca acclimated to 2.5 and $8.8 \mu \mathrm{mol}$ $\mathrm{m}^{-2} \mathrm{~s}^{-1}$ (Sand-Jensen 1988b). The minimum light level at which growth occurred with certainty without weight reductions in previous experiments at $10^{\circ} \mathrm{C}(1.7$ umol $\mathrm{m}^{-2} \mathrm{~s}^{-1}$; Vermaat \& Sand-Jensen 1987) was also close to the above level.

The $I_{c}$ value (umol $\mathrm{m}^{-2} \mathrm{~s}^{-1}$ ) is dependent on the respiratory maintenance rate $\left(r_{m} ; n m o l ~ C \mathrm{~cm}^{-2} h^{-1}\right)$, quantum efficiency $\left(\varnothing_{\mathrm{m}}\right)$, mol C (mol absorbed photon $)^{-1}$, light absorptance $(\mathrm{A})$, and a dimensional constant $\left(\mathrm{k} ; 2.78 \times 10^{-3}\right)$ :

$$
\mathrm{I}_{\mathrm{c}}=\mathrm{r}_{\mathrm{m}} \varnothing_{\mathrm{m}}^{-1} \mathrm{~A}^{-1} \times \mathrm{k}
$$

It is possible to consider how and to what extent $I_{c}$ may be reduced even further for Ulva lactuca using optimistic estimates for the variables on the right-hand side of Eq. (2) taken either from this investigation or from the literature. The gross growth efficiency at 2.5 $\mu \mathrm{mol} \mathrm{m}^{-2} \mathrm{~s}^{-1}$ was $0.056 \mathrm{molC}$ fixed (mol photon absorbed $)^{-1}$. This was a fair estimate of $\varnothing_{\mathrm{m}}$ since growth at $2.5 \mu \mathrm{mol} \mathrm{m} \mathrm{m}^{-2} \mathrm{~s}^{-1}$ was always light-limited. The maximum $\emptyset_{\mathrm{m}}$ found in photosynthetic experiments was only slightly higher at $0.059 \mathrm{~mol} \mathrm{C}$ (mol photon) ${ }^{-1}$ (Sand-Jensen 1988b). The theoretical upper limit, however, is higher at $0.10 \mathrm{~mol} C$ (mol photon $)^{-1}$, assuming a photosynthetic quotient of $1.25 \mathrm{~mol} \mathrm{O}_{2}(\mathrm{~mol} \mathrm{C})^{-1}$. The

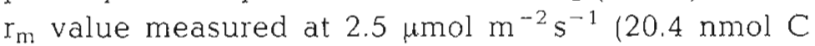
$\mathrm{cm}^{-2} \mathrm{~h}^{-1}$ ) was also only marginally higher than in the dark (18.8 nmol $\mathrm{C} \mathrm{cm}^{-2} \mathrm{~h}^{-1}$ ). Light absorptance (0.41), on the other hand, was clearly lower than at $8.8 \mathrm{kmol}$ $\mathrm{m}^{-2} \mathrm{~s}^{-1}(0.51)$. The most optimistic estimates from this investigation (i.e. $\varnothing_{\bar{m}}=0.059, r_{m}=18.8, A=0.51$ ) would lead to an $I_{c}$ value of $1.7 \mu \mathrm{mol} \mathrm{m} \mathrm{m}^{-2} \mathrm{~s}^{-1}$ which was still only slightly lower than the observed value. To bring $\mathrm{I}_{\mathrm{C}}$ down further there are 3 possible options: $\varnothing_{\mathrm{m}}$ should approach the theoretical upper limit, $I_{m}$ be reduced, and/or absorptance should increase. I am sceptical as to whether this may happen to any great extent. Maximum $\varnothing_{\mathrm{m}}$ values at ca $0.10 \mathrm{molC}$ (mol photon) ${ }^{-1}$ have been reported in photoadapted microalgae (Geider et al. 1985, 1986) but most literature values accord with those reported here at ca 0.05 to 0.06 mol C (mol photon) $^{-1}$ (Björkman 1981, Bannister \& Weidemann 1984). I have never observed the average absorptance in $U$. lactuca $(400$ to $700 \mathrm{~nm}$ ) to exceed 0.60. Minimum $I_{c}$ values are also not likely to be attained by absorptances above this value because of the progressively larger light-harvesting apparatus needed and thus higher $r_{m}$ values (Raven 1984b). This leaves maintenance costs as the most likely candidate for reduction of $I_{c}$, perhaps due to a decline in culture temperature. The $Q_{10}$ for respiration is usually about 2.0 to 2.5 when microalgae, for example, are taken from one temperature and examined over a temperature range in short-term experiments (Harris 1978). This response is a natural consequence of temperature effects on activity of the same enzyme pool and it would suggest a 2 -fold decrease in $I_{c}$ with a $10 \mathrm{C}^{\circ}$ decline within the temperature tolerance regime of the species. However, much lower, as well as much higher, $Q_{10}$ values have been reported, depending on species and temperature range. Furthermore, the true comparison should be made among plants adapted to low light at different temperatures. Such comparisons are rarely made for submerged macrophytes but those available indicate a smaller temperature effect than the $Q_{10}$ of 2 (Barko \& Smart 1981). Therefore, a decline of culture temperature of $U$. lactuca below $7^{\circ} \mathrm{C}$ will not necessarily reduce $\mathrm{r}_{\mathrm{m}}$. Furthermore, it is evident that low $I_{c}$ values for growth are not always associated with low temperatures but may also occur at high temperatures in species with a high temperature preference. The apparent low $I_{c}$ value of deep-growing tropical red algae (Littler \& Littler 1985) and of Phaeodactylum tricornutum at $22^{\circ} \mathrm{C}$ (Geider et al. 1986) supports this view.

Minimum light requirements for growth among 
unicellular algae are quite variable. Based upon a literature survey, Richardson et al. (1983) found that $I_{c}$ was, on the average, lower for diatoms and dinoflagellates $(6$ to $7 \mathrm{umol} \mathrm{m} \mathrm{m}^{-2} \mathrm{~s}^{-1}$ ) than for green algae (21 $\mu \mathrm{mol}$ $\mathrm{m}^{-2} \mathrm{~s}^{-1}$ ). Within all algal classes, there were observations of algal growth at light levels close to $1 \mu \mathrm{mol}$ $\mathrm{m}^{-2} \mathrm{~s}^{-1}$ or lower (Geider et al. 1986 and references therein). On theoretical grounds, Raven (1984b) predicted that microalgae, due to small internal shading among photosynthetic pigments, would achieve smaller $I_{c}$ values than macroalgae. Whether any generalization concerning algal size and $I_{c}$ values for growth is possible in reality, however, awaits further experimental analysis.

\section{Maintenance costs}

The preceding discussion highlights the importance of the maintenance respiratory requirements $\left(r_{m}\right)$ for the $I_{c}$ value of aquatic plants. Extremely low $r_{m}$ values are clearly a prerequisite for the ability of microalgae and macroalgae to grow with less than $1 \%$ of surface light available. The dark respiration rates of Ulva lactuca increased linearly with the growth rate, a common response also among unicellular microalgae (Laws \& Caperon 1976, Richardson et al. 1983). In low light (0 to $\left.0.3 \mu \mathrm{mol} \mathrm{m} \mathrm{m}^{-2} \mathrm{~s}^{-1}\right)$, where growth did not occur and dark respiration rates accordingly represented maintenance costs, the rates stayed within a small range from 0.0094 to $0.012 \mathrm{~mol} \mathrm{C}$ (mol cell C) $)^{-1} \mathrm{~d}^{-1}\left(1.1\right.$ to $\left.1.4 \times 10^{-7} \mathrm{~s}^{-1}\right)$. Estimates of $r_{m}$ of unicellular algae, based on considerations of the energetics of species with very low $I_{c}$ values $\left(0.1\right.$ to $\left.1 \mu \mathrm{mol} \mathrm{m} \mathrm{m}^{-2} \mathrm{~s}^{-1}\right)$, were of similar magnitude between 0.4 and $3.7 \times 10^{-7} \mathrm{~s}^{-1}$ (Geider et al. 1986). By contrast, the direct experimentally derived $\mathrm{r}_{\mathrm{m}}$ values for microalgae were an order of magnitude higher, between 6 and $17 \times 10^{-7} \mathrm{~s}^{-1}$ (Geider et al. 1985 and references therein). There are at least 2 possible explanations for this discrepancy. (1) The experimental respiration rates are too high due to disturbance of the algae prior and during the experiment, usually performed in oxygen chambers with intense stirring over short time intervals. (2) The estimated $I_{c}$ values are too low due to non-steady state growth conditions or errors in estimating the incident light level. These aspects deserve more careful examination in future.

In the present experiment I did not find this discrepancy, possibly because I tried to maintain the same stirring intensity during acclimation as well as during experiments, ran the experiments over $18 \mathrm{~h}$, and accounted for the non-steady state growth conditions.

In conclusion, UIva lactuca is able to grow at very low photon flux densities. It optimizes its efficiency for utilizing low light by increasing light-harvesting capa- city and by reducing respiratory maintenance costs. The light compensation point and maintenance costs for U. lactuca are of the same magnitude as those for many shade-adaptive microalgae. There are often major discrepancies between the energetics of algae derived from growth experiments and direct measurements of photosynthetic and respiratory rates, possibly due to experimental errors. Here, however, the 2 types of experiments were in close agreement.

The shade tolerance demonstrated here accords with our recent observations of large amounts of Ulva lactuca occurring at great depths in eutrophicated estuaries. On the other hand, U. lactuca is more abundant in shallow than deep water of most habitats. This is a logical consequence of a better net balance in shallow water between biomass growth and biomass losses, for instance due to grazing. Invertebrate grazing is often intensive on $U$. lactuca and may easily remove all biomass particularly when growth is retarded (Gertz-Hansen \& Sand-Jensen unpubl.). It follows that slow-growing, grazing-resistant species may dominate at great depths not because of a greater ability to photosynthesize and grow in the shade, but due to an ability to maintain their biomass. U. lactuca is often regarded as a ruderal sun plant. This investigation clearly shows that light requirements for growth are small in $U$. lactuca and there is no physiological basis for using this term.

Acknowledgements. This work was partially supported by the Danish Natural Science Research Council, the Carlsberg Foundation, and the Danish Agency for Environmental Protection.

\section{LITERATURE CITED}

Bannister, T T., Weidemann, A. D. (1984). The maximum quantum yield of phytoplankton photosynthesis in situ. $J$. Plankton Res. 6: 275-294

Barko, J. W., Hardin, D. G., Matthews, M. S. (1982). Growth and morphology of submersed freshwater macrophytes in relation to light and temperature. Can. J. Bot. 60: 877-887

Barko, J. W., Smart, R. M. (1981.). Comparative influences of light and temperature on growth and metabolism of selected submersed freshwater macrophytes. Ecol. Monogr 51. 219-235

Björkman, O. (1981). Responses to different quantum flux densities. In: Lange, O L., Nobel, P. S., Osmond, C. B., Ziegler, H. (ed.) Encyclopedia of plant physiology, Vol. 12A, Physiological plant ecology I, Responses to the physical environment. Springer-Verlag, Berlin, p. 57-107

Borum, J. (1985). Development of epiphytic communities on eelgrass (Zostera marina) along a nutrient gradient in a Danish estuary Mar. Biol. 87. 233-241

Chambers, P. A., Kalff, J. (1985). Depth distribution of biomass of submerged aquatic macrophyte communities in relation to Secchi depth. Can. J. Fish. Aquat. Sci. 42: 701-709

Fee, E. J. (1976). The vertical and seasonal distribution of chlorophyll in lakes of the Experimental Lakes Area, 
Northwestern Ontario: implications for primary production. Limnol. Oceanogr. 21. 767-783

Geider, R. J., Osborne, B. A., Raven, J. A. (1985). Light dependence of growth and photosynthesis in Phaeodactylum tricornutum (Bacillariophyceae). J. Phycol. 21: 609-619

Geider, R. J., Osborne, B. A., Raven, J. A. (1986). Growth, photosynthesis and maintenance metabolic cost in the diatom Phaeodactylum tricornutum at very low light levels. J. Phycol. 22: 39-48

Harris, G. P. (1978). Photosynthesis, productivity and growth the physiological ecology of phytoplankton. Ergebn. Limnol. 10: 1-171

Laws, E. A., Caperon, J. (1976). Carbon and nitrogen metabolism by Monochrysis lutheri: measurements of growth-ratedependent respiration rates. Mar. Biol. 36: 85-97

Littler, M. M., Littler, D. S. (1985). Deepest known plant life discovered on an uncharted seamount. Science $227 \cdot 57-59$

Lüning, K., Dring, M. J. (1979). Continuous underwater light measurements in the sublittoral region. Helgoländer wiss. Meeresunters. 32: 403-424

Moeller, R. (1980). The temperature-determined growing season of a submerged hydrophyte: tissue chemistry and biomass turnover of Utricularia purpurea. Freshwat. Biol. 10: $391-400$

Pick, F. R., Nalewajko, C., Lean, D. R. S. (1984). The origin of a metalimnetic chrysophyte peak. Limnol. Oceanogr. 29: $125-134$
Ramus, J. (1978). Seaweed anatomy and photosynthetic performance: the ecological significance of light guides. heterogeneous absorption and multiple scatter. J. Phycol 14: $352-360$

Raven, J. A. (1984a). Energetics and transport in aquatic plants. Alan R. Liss, New York

Raven, J. A. (1984b). A cost-benefit analysis of photon absorption by photosynthetic unicells. New Phytol. 98: 593-625

Richardson, K., Beardall, J., Raven, J. A. (1983). Adaptation of unicellular algae to irradiance: an analysis of strategies. New Phytol. 93: 157-191

Sand-Jensen, K. (1988a). Environmental variables and their effect on photosynthesis of pelagial and littoral plant communities. In: Bowes, G. (ed.) Aquatic photosynthesis and photorespiration. Elsevier, Amsterdam (in press)

Sand-Jensen, K. (1988b). Photosynthetic responses of Ulva lactuca at very low light. Mar. Ecol. Prog. Ser. 50: 195-201

Steemann-Nielsen, E. (1975). Marine photosynthesis with special emphasis on the ecological aspects. Elsevier, Amsterdam

Venrick, E. L., McGowan, J. A., Mantyla, A. W (1973). Deep chlorophyll a maxima of photosynthetic pigments in the Pacific Ocean. Fish. Bull. U.S. 71, 41-52

Vermaat, J. E., Sand-Jensen, K. (1987). Survival, metabolism and growth of Ulva lactuca L. under winter conditions: a laboratory study of bottlenecks in the life cycle. Mar. Biol. 95: $55-61$ 